\title{
The effect of primary tumor radiotherapy in patients with Unresectable stage IV Rectal or Rectosigmoid Cancer: a propensity score matching analysis for survival
}

Gang Wang, Wenling Wang ${ }^{*}$, Haijie Jin, Hongmin Dong, Weiwei Chen, Xiaokai Li, Guodong Li and Leilei Li

\begin{abstract}
Background: To evaluate the impact of primary tumor radiotherapy on survival in patients with unresectable metastatic rectal or rectosigmoid cancer.

Methods: From September 2008 to September 2017, 350 patients with unresectable metastatic rectal or rectosigmoid cancer were retrospectively reviewed in our center. All patients received at least 4 cycles of chemotherapy and were divided into two groups according to whether they received primary tumor radiotherapy. A total of 163 patients received primary tumor radiotherapy, and the median radiation dose was 56.69 Gy (50.4-60). Survival curves were estimated with the Kaplan-Meier method to roughly compare survival between the two groups. Subsequently, the 18-month survival rate was used as the outcome variable for this study. This study mainly evaluated the impact of primary tumor radiotherapy on the survival of these patients through a series of multivariate Cox regression analyses after propensity score matching (PSM).

Results: The median follow-up time was 21 months. All 350 patients received a median of 7 cycles of chemotherapy (range 4-12), and 163 (46.67\%) patients received primary tumor radiotherapy for local symptoms. The Kaplan-Meier survival curves showed that the primary tumor radiotherapy group had a significant overall survival (OS) advantage compared to the group without radiotherapy (20.07 vs 17.33 months; $P=0.002$ ). In this study, the multivariate Cox regression analysis after adjusting for covariates, multivariate Cox regression analysis after PSM, inverse probability of treatment weighting (IPTW) analysis and propensity score (PS)-adjusted model analysis consistently showed that primary tumor radiotherapy could effectively reduce the risk of death for these patients at 18 months (HR: 0.62, 95\% Cl 0.40-0.98; HR: 0.79, 95\% Cl: 0.93-1.45; HR: 0.70, 95\% Cl 0.55-0.99 and HR: $0.74,95 \% \mathrm{Cl}: 0.59-0.94)$.
\end{abstract}

Conclusion: Compared with patients with stage IV rectal or rectosigmoid cancer who did not receive primary tumor radiotherapy, those who received primary tumor radiotherapy had a lower risk of death. The prescription dose (59.4 Gy/33 fractions or $60 \mathrm{~Gy} / 30$ fractions) of radiation for primary tumors might be considered not only to relieve symptoms improve the survival of patients with inoperable metastatic rectal or rectosigmoid cancer.

Keywords: Stage IV rectal cancer, Primary tumor radiotherapy, Propensity score matching

\footnotetext{
* Correspondence: 3080238266@qq.com

Department of Abdominal Oncology, The Affiliated Hospital of Guizhou Medical University, Guizhou Cancer Hospital, Guiyang 550004, People's Republic of China
}

(c) The Author(s). 2020 Open Access This article is licensed under a Creative Commons Attribution 4.0 International License, which permits use, sharing, adaptation, distribution and reproduction in any medium or format, as long as you give appropriate credit to the original author(s) and the source, provide a link to the Creative Commons licence, and indicate if changes were made. The images or other third party material in this article are included in the article's Creative Commons licence, unless indicated otherwise in a credit line to the material. If material is not included in the article's Creative Commons licence and your intended use is not permitted by statutory regulation or exceeds the permitted use, you will need to obtain permission directly from the copyright holder. To view a copy of this licence, visit http://creativecommons.org/licenses/by/4.0/ The Creative Commons Public Domain Dedication waiver (http://creativecommons.org/publicdomain/zero/1.0/) applies to the data made available in this article, unless otherwise stated in a credit line to the data. 


\section{Background}

From the cancer statistical data of 2019, the incidence rate of colorectal cancer was 39.42 per 100,000 population in the U.S. [1], and the rate was 27.47 per 100,000 people in China [2]. The proportion of rectal cancer among colorectal cancers was $49.7 \%$ in China, which is higher than the corresponding $30.4 \%$ in the U.S. Approximately $25 \%$ of colorectal cancer patients present have overt metastases, and an additional $25-35 \%$ of patients will develop metastases during the course of their disease [3]. Approximately $80-90 \%$ of patients with metastatic colorectal cancer were not able to undergo a radical surgery of metastatic lesions $[3,4]$, therefore a surgical removal to the primary tumor was considered unnecessary, which leads to the fact that most of stage IV rectal cancer are always with primary lesion in their whole survival time. Benefitting from the combination therapies of chemotherapy and targeted drugs, unresectable stage IV colorectal cancer normally has a median survival time of 20.7-33.4 months, which has been reported by several classical studies [5-8]. At present, systemic chemotherapy is still the preferred treatment for stage IV unresectable colorectal cancer.
Radiotherapy or resection of the primary tumor is only recommended for patients with primary tumor progression by the National Comprehensive Cancer Network (NCCN) guidelines [9]. These patients usually have typical local symptoms such as obstruction, bleeding, and pain. Although there is some controversy, most of the studies show that resection of the primary tumor without metastasectomy not only relieves pelvic symptoms in patients but also improves their survival [1012]. However, few studies have explored whether radiotherapy for primary tumors can also improve the survival of these patients. To provide more meaningful clinical evidence to answer this question, in this study, we retrospectively analyzed 350 patients with stage IV unresectable rectal or rectosigmoid cancer using propensity score matching (PSM) analyses to explore whether there were any survival benefits in patients who received primary tumor radiotherapy.

\section{Methods}

We retrospectively reviewed 366 patients who were initially diagnosed with stage IV unresectable rectal or rectosigmoid cancer from September 2008 to September

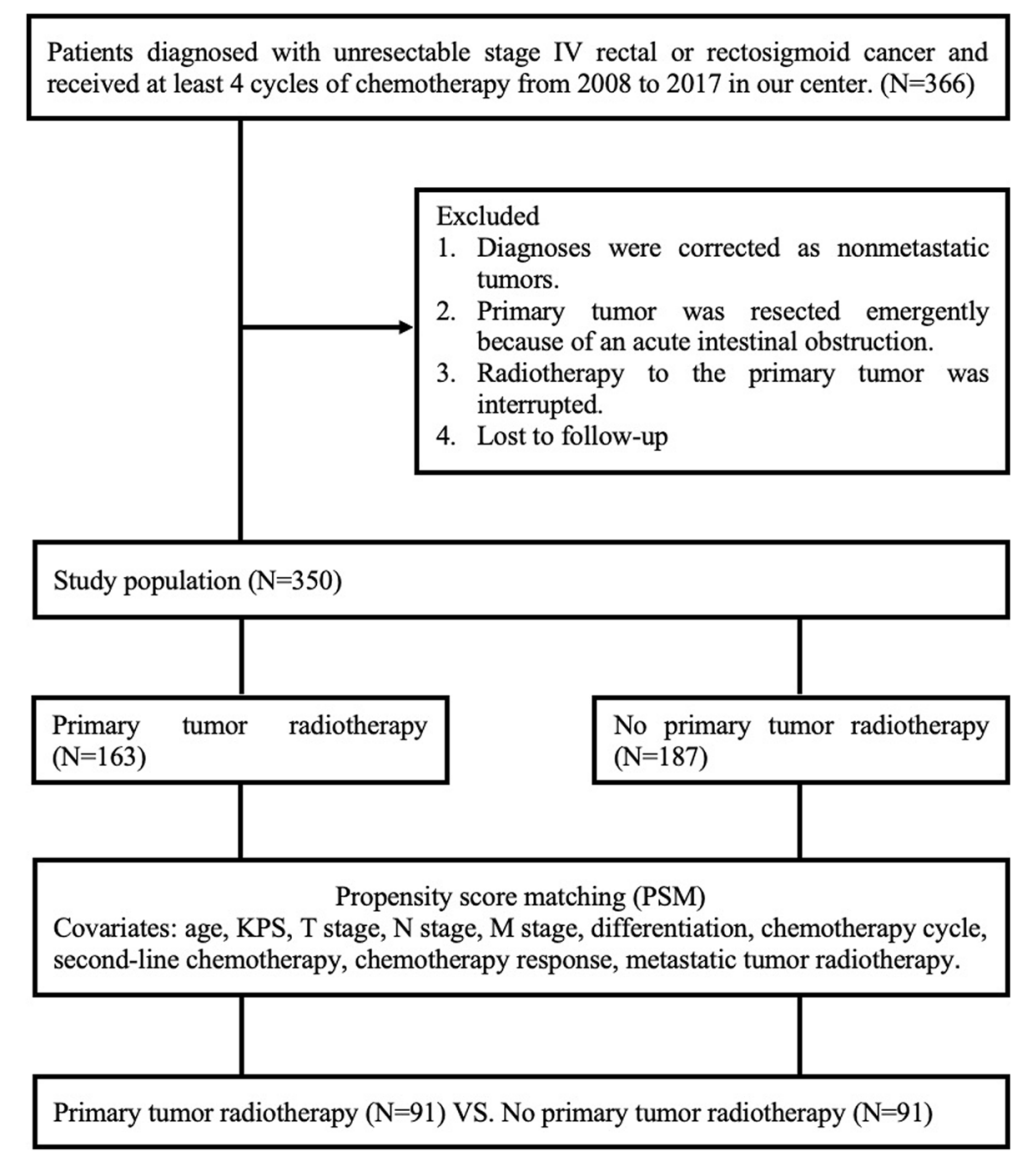

Fig. 1 Flow diagram of the PSM process 
Table 1 Comparison of clinical and treatment characteristics between the patients with primary tumor radiation and those without

\begin{tabular}{|c|c|c|c|c|c|}
\hline \multirow[t]{3}{*}{ Variable } & \multicolumn{4}{|c|}{ Primary tumor radiotherapy } & \multirow[t]{3}{*}{$\boldsymbol{P}$-value } \\
\hline & \multicolumn{2}{|l|}{ No (187) } & \multicolumn{2}{|l|}{ Yes (163) } & \\
\hline & Number & $\%$ & Number & $\%$ & \\
\hline Age & & & & & 0.460 \\
\hline$<60$ years & 90 & 48.13 & 72 & 44.17 & \\
\hline$\geq 60$ years & 97 & 51.87 & 91 & 55.83 & \\
\hline Sex & & & & & 0.879 \\
\hline Male & 136 & 72.73 & 118 & 72.39 & \\
\hline Female & 51 & 27.27 & 45 & 27.61 & \\
\hline $\mathrm{KPS}^{\mathrm{a}}$ & & & & & 0.037 \\
\hline $70-80$ & 120 & 64.17 & 122 & 74.85 & \\
\hline $90-100$ & 67 & 35.83 & 41 & 25.15 & \\
\hline Primary Site & & & & & 0.056 \\
\hline Rectum & 134 & 71.66 & 132 & 80.98 & \\
\hline Rectosigmoid & 53 & 28.34 & 31 & 19.02 & \\
\hline T Stage & & & & & 0.043 \\
\hline $\mathrm{T} 2$ & 10 & 5.35 & 14 & 8.59 & \\
\hline T3 & 86 & 45.99 & 90 & 55.21 & \\
\hline T4 & 91 & 48.66 & 59 & 36.20 & \\
\hline N Stage & & & & & $<0.001$ \\
\hline No & 10 & 5.35 & 40 & 24.54 & \\
\hline N1 & 43 & 22.99 & 71 & 43.56 & \\
\hline N2 & 44 & 23.53 & 42 & 25.77 & \\
\hline $\mathrm{N}+$ & 77 & 41.18 & 9 & 5.52 & \\
\hline Nx & 13 & 6.95 & 1 & 0.61 & \\
\hline M Stage & & & & & 0.880 \\
\hline M1a & 98 & 52.41 & 82 & 50.31 & \\
\hline $\mathrm{M} 1 \mathrm{~b}$ & 77 & 41.17 & 69 & 42.33 & \\
\hline $\mathrm{M} 1 \mathrm{C}$ & 12 & 6.42 & 12 & 7.36 & \\
\hline Differentiation & & & & & 0.013 \\
\hline Well & 20 & 10.70 & 8 & 4.91 & \\
\hline Moderate & 94 & 50.27 & 104 & 63.80 & \\
\hline Poor & 61 & 32.62 & 49 & 30.06 & \\
\hline Unknown & 12 & 6.42 & 2 & 1.23 & \\
\hline Chemotherapy Cycle & & & & & 0.019 \\
\hline $4-8$ cycles & 142 & 75.94 & 105 & 64.42 & \\
\hline 9-12 cycles & 45 & 24.06 & 58 & 35.58 & \\
\hline Second-line Chemotherapy & & & & & 0.014 \\
\hline No & 156 & 83.42 & 120 & 73.62 & \\
\hline Yes & 31 & 16.58 & 43 & 26.38 & \\
\hline Chemotherapy Response & & & & & 0.279 \\
\hline Poor & 83 & 44.39 & 63 & 38.65 & \\
\hline Good & 104 & 55.61 & 100 & 61.35 & \\
\hline Metastatic Tumor Radiotherapy & & & & & 0.201 \\
\hline Yes & 90 & 48.13 & 90 & 55.21 & \\
\hline No & 97 & 51.87 & 73 & 44.79 & \\
\hline
\end{tabular}

${ }^{\mathrm{a}}$ KPS Karnofsky Performance Status 


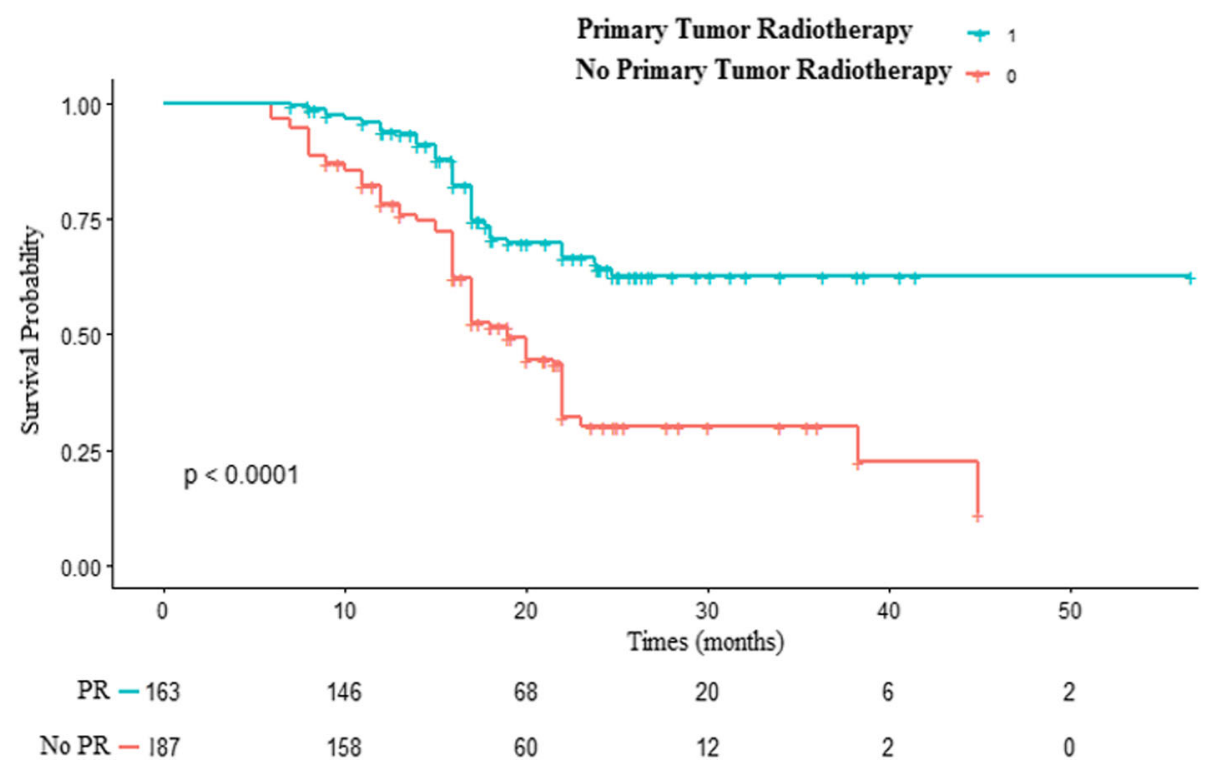

Fig. 2 Kaplan-Meier curves for primary tumor radiotherapy and no primary tumor radiotherapy

2017 in our center. All patients received at least 4 cycles of chemotherapy, some of whom had significant local pelvic symptoms and received primary tumor radiotherapy. Four patients' diagnoses were corrected as nonmetastatic patients by review, 3 patients underwent emergency resection of the primary tumor because of an acute intestinal obstruction, 4 patients discontinued primary tumor radiotherapy, and 5 patients were lost to follow-up. The final analysis included 350 patients, and the details of the PSM process are demonstrated in Fig. 1. Of these 350 patients, 254 were male, and 96 were female; 266 were diagnosed with rectal cancer, and 84 had rectosigmoid cancer. The numbers of patients with stage IVa, IVb and IVc disease were 180, 146 and 24, respectively, according to the 8th edition of the American Joint Commission on Cancer (AJCC) Cancer Staging Manual. The whole group of patients received chemotherapy (FOLFOX4/FOLFOX6), and the average number of chemotherapy cycles was 7 cycles. Seventy-four patients received second-line chemotherapy after disease progression. The response to chemotherapy was assessed by the Response Evaluation Criteria in Solid Tumors (RECIST); partial response (PR) or stable disease (SD) was defined as a good response to chemotherapy, and progressive disease (PD) was defined as a poor response. Because of typical local pelvic symptoms such as pain, bleeding, and incomplete obstruction, 163 patients received primary tumor radiotherapy while receiving chemotherapy. Intensity-modulated radiotherapy (IMRT) was used as primary tumor radiotherapy. Primary tumors included intestinal tumors and metastatic lymph nodes confirmed by pelvic computed tomography (CT) or magnetic resonance imaging (MRI). Radiotherapy was administered at doses of 1.8 or $2.0 \mathrm{~Gy} /$ day and delivered 5 days per week for a total dose of 59.4 or $60 \mathrm{~Gy}$. The pelvic lymph drainage area (presacral space, internal iliac, obturator, mesorectum) within $2 \mathrm{~cm}$ above and below the primary tumor received $45-50.4 \mathrm{~Gy}$. The patient and treatment characteristics are shown in Table 1.

The follow-up period was defined as the time from the confirmed diagnosis of metastatic colorectal cancer until death or at least 18 months after the confirmed diagnosis. The survival time of the two groups was compared with the Kaplan-Meier method. The outcome variable was the 18-month survival rate, and whether the primary tumor was treated with radiation was used as the exposure variable. Covariates that may be related to outcome variables were screened for by referring to previous literature, clinical experience, and univariate Cox regression analysis. Multivariate Cox regression analysis was used to identify the independent effects of exposure variables on the outcome variable after adjusting for relevant covariates. This study was a retrospective observational study, not a randomized controlled trial (RCT), so selection bias was inevitable. To minimize the effect of bias, the propensity score matching (PSM) method can achieve a similar randomization effect, further verifying the previous analysis results. The matching algorithm used binary logistic regression, and the caliper value was set to 0.05. Given that PSM can cause sample loss, this study used inverse probability of treatment weighting (IPTW) as a sensitivity analysis to assess the stability of the results. Moreover, we further verified the results by adjusting the propensity score analysis (PS-adjusted 
Table 2 Univariable Cox regression analysis of factors affecting survival at 18 months in the whole group of patients

\begin{tabular}{|c|c|c|c|}
\hline Factors & Number (\%) & HR $(95 \% \mathrm{Cl})$ & $\boldsymbol{P}$ value \\
\hline \multicolumn{4}{|l|}{ Age } \\
\hline$<60$ years & $162(46.29)$ & Reference & \\
\hline$\geq 60$ years & 188 (53.71) & $0.98(0.97,1.00)$ & 0.0297 \\
\hline \multicolumn{4}{|l|}{ Sex } \\
\hline Male & $254(72.57)$ & Reference & \\
\hline Female & $96(27.43)$ & $0.88(0.62,1.26)$ & 0.4927 \\
\hline \multicolumn{4}{|l|}{ KPS } \\
\hline $70-80$ & $242(69.14)$ & Reference & \\
\hline $90-100$ & $108(30.86)$ & $1.00(0.98,1.03)$ & 0.7220 \\
\hline \multicolumn{4}{|l|}{ Primary Site } \\
\hline Rectum & $266(76.00)$ & Reference & \\
\hline Rectosigmoid & $84(24.00)$ & $1.12(0.53,1.18)$ & 0.6210 \\
\hline \multicolumn{4}{|l|}{ T Stage } \\
\hline $\mathrm{T} 2$ & $24(6.86)$ & Reference & \\
\hline T3 & $176(50.29)$ & $2.86(1.05,7.83)$ & 0.0406 \\
\hline T4 & $150(42.86)$ & $3.16(1.15,8.64)$ & 0.0253 \\
\hline \multicolumn{4}{|l|}{ N Stage } \\
\hline No & $50(14.29)$ & Reference & \\
\hline N1 & $114(32.57)$ & $0.88(0.44,1.75)$ & 0.7192 \\
\hline $\mathrm{N} 2$ & $86(24.57)$ & $2.03(1.05,3.93)$ & 0.0350 \\
\hline $\mathrm{N}+$ & $86(24.57)$ & $4.09(2.21,7.59)$ & $<0.0001$ \\
\hline Nx & $14(4.00)$ & $7.01(3.14,15.66)$ & $<0.0001$ \\
\hline
\end{tabular}

\section{Stage}

M1a

$\mathrm{M} 1 \mathrm{~b}$

M1c

Differentiation

$\begin{array}{ll}\text { Well } & 28(8.00) \\ \text { Moderate } & 198(56.57) \\ \text { Poor } & 110(31.43) \\ \text { Unknown } & 14(4.00)\end{array}$

\section{Chemotherapy Cycles}

4-8 247(70.57) Reference

9-12 103(29.43)

Second-line Chemotherapy

$\begin{array}{ll}\text { No } & 276(78.86) \\ \text { Yes } & 74(21.14)\end{array}$

Chemotherapy Response

$\begin{array}{ll}\text { Poor } & 146(41.71) \\ \text { Good } & 204(58.29)\end{array}$

\section{Metastatic Tumor radiotherapy}

Yes

No
180 (51.43)

$170(48.57)$
Reference $0.82(0.59,1.13) \quad 0.0217$

Reference

$1.09(0.77,1.54)$

0.6163

0.0006

Reference

$0.28(0.17,0.47)$

$1.00(0.61,1.65)$

$0.95(0.22,4.07)$

$0.79(0.69,0.90)$

Reference

$0.37(0.22,0.63)$

0.0002

$<0.0001$

0.9877

0.9444

0.0002

Reference

$1.53(1.11,2.11)$
Table 2 Univariable Cox regression analysis of factors affecting survival at 18 months in the whole group of patients (Continued)

\begin{tabular}{lrlr}
\hline Factors & Number $(\%)$ & HR $(95 \% \mathrm{Cl})$ & $\boldsymbol{P}$ value \\
\hline \multicolumn{2}{l}{ Primary Tumor Radiotherapy } & & \\
No & $187(53.43)$ & Reference & \\
Yes & $163(46.57)$ & $0.39(0.28,0.56)$ & $<0.0001$ \\
\hline
\end{tabular}

model). Statistical analyses were performed using SPSS software (version 24.0, SPSS, Chicago, IL, USA) and R software.

\section{Results}

The median follow-up time was 21 months. Patients who received primary tumor radiotherapy had more cycles of chemotherapy $(35.58 \%$ vs $24.06 \% ; P=0.019)$ and were more likely to receive second-line chemotherapy $(26.38 \%$ vs $16.58 \% ; P=0.014$ ) than those who did not receive primary tumor radiotherapy. Patients with a lower Karnofsky performance status (KPS) score, moderate differentiation and T3 stage constituted a higher percentage in the primary tumor radiotherapy group. All of the other characteristics were similar between groups (Table 1).

The Kaplan-Meier survival curves showed that the primary tumor radiotherapy group had a significant overall survival (OS) advantage compared to the group without radiotherapy (20.07 vs 17.33 months; $P=0.002$; Fig. 2). The 18-month survival rates were 73.01 and $42.25 \%$, respectively, for the groups with and without primary tumor radiotherapy.

Univariable Cox regression analysis was performed to assess the associations between covariates and the 18month survival rate, and the results are displayed in Table 2. The possible protective factors based on the univariable Cox regression analysis include older age, more chemotherapy cycles, second-line chemotherapy, better chemotherapy response, metastatic lesions treated with radiotherapy, and primary tumor treated with radiotherapy. The possible risk factors include a higher $\mathrm{T}$ stage, $\mathrm{N}$ stage, and $M$ stage. Based on the univariate Cox regression analysis and the distribution of related factors in the two groups of patients, 10 variables (including age, KPS, T stage, $\mathrm{N}$ stage, $\mathrm{M}$ stage, differentiation, chemotherapy cycle, second-line chemotherapy, chemotherapy response, radiotherapy for metastatic tumor) were selected as the covariates that needed to be adjusted for in subsequent multivariate Cox regression analysis. After adjusting for the above covariates in the multivariate Cox regression analysis, the primary tumor radiotherapy group had a lower risk of death than the group without primary tumor radiotherapy (HR: 0.62, 95\% CI 0.40-0.98; Table 4). The 10 variables were included in propensity score matching. There were 91 matched patients in each group after 1:1 
individual matching without replacement. The matching situation is shown in Fig. 3, and the clinicopathological features are presented in Table 3. The primary tumor radiotherapy group still showed a lower risk of death than the group without primary tumor radiotherapy after propensity score matching (HR: 0.79, 95\% CI: 0.93-1.45; Table 4). The sensitivity analyses using propensity scorebased IPTW and PS-adjusted models yielded similar results (Table 4). The results from our sensitivity analyses were consistent with our primary analysis findings. Patients treated with primary tumor radiotherapy in this study had a lower risk of death than those treated without radiotherapy (HR: 0.70, 95\% CI $0.55-0.99$ and HR: 0.74, 95\% CI: 0.59-0.94).

\section{Discussion}

With the application of oxaliplatin and irinotecan in combination with the fluorouracil regimen, the survival time of stage IV colorectal cancer ranged from 16 to 20 months [13-15]. After entering the era of targeted drugs combined with chemotherapy, the survival time of stage IV colorectal cancer has been significantly improved to 20.733.4 months.
For patients with stage IV colorectal cancer who cannot be cured by radical surgery, in general, resection or radiotherapy was used as a local treatment to relieve local obstruction, hemorrhage and pain. More clinical studies focus on the benefits of primary tumor resection alone. Although there are still controversies at present $[16,17]$, most of the existing clinical studies show that resection of the primary tumor alone can not only reduce the incidence of local complications [18] but also seems to be beneficial in terms of patient survival [11, 19, 20]. However, there are limited data regarding the effect of primary tumor radiotherapy in stage IV unresectable rectal or rectosigmoid cancer, and most of these studies mainly observed the palliative effect [21-24]. To the best of our knowledge, very few studies have explored the effects of primary tumor radiotherapy on the survival of metastatic rectal cancer. For clinical researchers, the main reason is that there are many factors that can affect the survival of patients with stage IV rectal cancer, and there are large individual differences. In retrospective observational studies, conventional multivariate regression analysis has difficulty effectively removing interference of confounding factors and

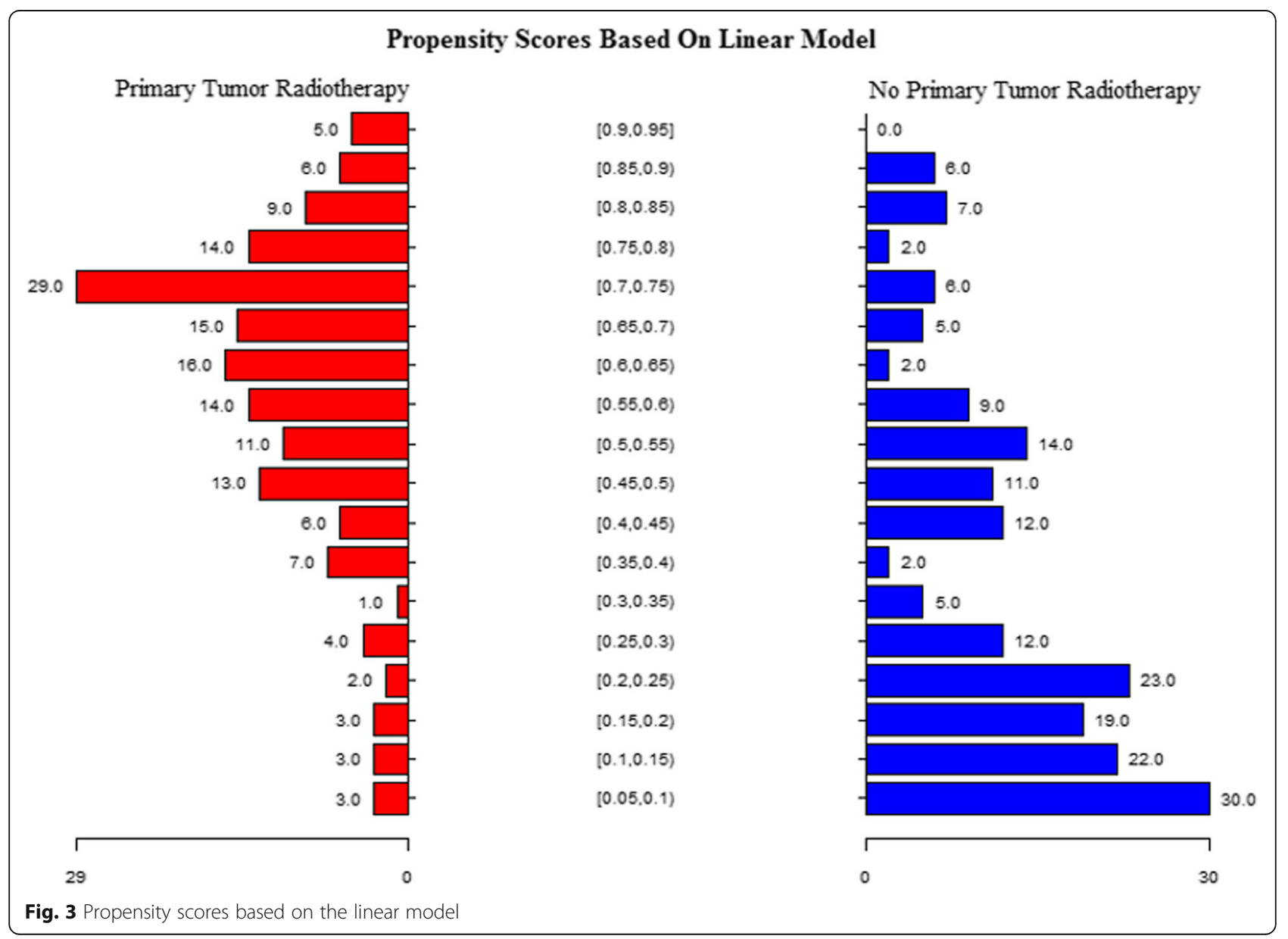


Table 3 Clinicopathological features between the two groups after propensity score matching

\begin{tabular}{|c|c|c|c|c|c|c|}
\hline \multirow[t]{3}{*}{ Variable } & \multicolumn{4}{|c|}{ Primary Tumor Radiotherapy } & \multirow{3}{*}{$\begin{array}{l}\text { Standardized } \\
\text { difference }\end{array}$} & \multirow[t]{3}{*}{$\boldsymbol{P}$ value } \\
\hline & \multicolumn{2}{|l|}{ No (91) } & \multicolumn{2}{|l|}{ Yes (91) } & & \\
\hline & Number & $\%$ & Number & $\%$ & & \\
\hline Age & & & & & 0.0224 & 1.0000 \\
\hline$<60$ years & 43 & 47.3 & 44 & 48.4 & & \\
\hline$\geq 60$ years & 48 & 52.7 & 47 & 51.6 & & \\
\hline KPS & & & & & & 0.1700 \\
\hline 70 & 14 & 15.4 & 32 & 35.2 & 0.4674 & \\
\hline 80 & 65 & 71.4 & 42 & 46.2 & 0.5313 & \\
\hline 90 & 12 & 13.2 & 14 & 15.4 & 0.0628 & \\
\hline 100 & 0 & 0.0 & 3 & 3.3 & 0.2611 & \\
\hline T Stage & & & & & & 0.1156 \\
\hline $\mathrm{T} 2$ & 10 & 11.0 & 5 & 5.5 & 0.2008 & \\
\hline T3 & 43 & 47.3 & 56 & 61.5 & 0.2898 & \\
\hline T4 & 38 & 41.8 & 30 & 33 & 0.1825 & \\
\hline N Stage & & & & & & 0.1250 \\
\hline No & 10 & 11.0 & 15 & 16.5 & 0.1601 & \\
\hline N1 & 44 & 48.4 & 29 & 31.9 & 0.3412 & \\
\hline N2 & 25 & 27.5 & 38 & 41.8 & 0.3037 & \\
\hline $\mathrm{N}+$ & 9 & 9.9 & 7 & 7.7 & 0.0777 & \\
\hline $\mathrm{Nx}$ & 3 & 3.3 & 2 & 2.2 & 0.0673 & \\
\hline M Stage & & & & & & 0.9395 \\
\hline M1a & 50 & 54.9 & 50 & 54.9 & 0.0000 & \\
\hline $\mathrm{M} 1 \mathrm{~b}$ & 37 & 40.7 & 36 & 39.6 & 0.0224 & \\
\hline M1c & 4 & 4.4 & 5 & 5.5 & 0.0507 & \\
\hline Differentiation & & & & & & 0.3212 \\
\hline Well & 7 & 7.7 & 6 & 6.6 & 0.0427 & \\
\hline Moderate & 53 & 58.2 & 52 & 57.1 & 0.0222 & \\
\hline Poor & 28 & 30.8 & 33 & 36.3 & 0.1166 & \\
\hline Unknown & 3 & 3.3 & 0 & 0 & 0.2611 & \\
\hline Chemotherapy Cycles & & & & & & 0.0940 \\
\hline 4 & 20 & 22.0 & 25 & 27.5 & 0.1276 & \\
\hline 5 & 5 & 3.3 & 0 & 0 & 0.2611 & \\
\hline 6 & 22 & 24.2 & 19 & 20.9 & 0.0790 & \\
\hline 8 & 20 & 22.0 & 14 & 15.4 & 0.1698 & \\
\hline 10 & 5 & 5.5 & 20 & 22 & 0.4932 & \\
\hline 12 & 19 & 20.9 & 13 & 14.3 & 0.1739 & \\
\hline Second-line Chemotherapy & & & & & 0.0000 & 1.0000 \\
\hline No & 74 & 81.3 & 74 & 81.3 & & \\
\hline Yes & 17 & 18.7 & 17 & 18.7 & & \\
\hline Chemotherapy Response & & & & & 0.1562 & 0.3680 \\
\hline Poor & 42 & 46.2 & 35 & 38.5 & & \\
\hline Good & 49 & 53.8 & 56 & 61.5 & & \\
\hline Metastatic Tumor Radiotherapy & & & & & 0.0880 & 0.6565 \\
\hline Yes & 44 & 48.4 & 48 & 52.7 & & \\
\hline No & 47 & 51.6 & 43 & 47.3 & & \\
\hline
\end{tabular}


Table 4 Various analysis models for the risk of death at 18 months in the two groups of patients

\begin{tabular}{|c|c|c|c|}
\hline \multirow[t]{3}{*}{ Methods } & \multicolumn{3}{|c|}{ Primary Tumor Radiotherapy } \\
\hline & \multirow[t]{2}{*}{ No } & \multicolumn{2}{|l|}{ Yes } \\
\hline & & $\mathrm{HR}(95 \% \mathrm{Cl})$ & $\boldsymbol{P}$ value \\
\hline cOX adjusted $^{a}$ & Reference & $0.62(0.40-0.98)$ & 0.0394 \\
\hline PSM model & Reference & $0.79(0.93-1.45)$ & NS \\
\hline IPTW model & Reference & $0.70(0.55-0.99)$ & 0.0436 \\
\hline PS-Adjusted ${ }^{b}$ & Reference & $0.74(0.50-0.94)$ & 0.0254 \\
\hline
\end{tabular}

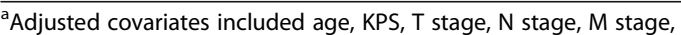
differentiation, chemotherapy cycle, second-line chemotherapy, chemotherapy response, and metastatic lesion radiotherapy

${ }^{\mathrm{b}}$ Propensity scores were adjusted

NS Not significant

selection bias from the results, which makes the analysis results lack reliability and consistency. Moreover, it is very difficult to implement such randomized controlled trials; for example, two previous trials (NCT01086618 and NCT01978249) were terminated due to recruitment problems. This study designed a series of analyses based on PSM to minimize interference from other confounding factors and selection bias on the research results.

In previous clinical studies on primary tumor radiotherapy for metastatic rectal cancer, the radiotherapy doses were generally low. Sager et al. reviewed many studies in which the radiotherapy dose delivered to the primary tumors ranged from 25 to $50 \mathrm{~Gy}$ [25]. When the $\alpha / \beta$ of the tumor was assumed to be $10 \mathrm{~Gy}$ for the biologically equivalent dose (BED), the BED of the above studies ranged from 37.5 to $53.1 \mathrm{~Gy}$. In this study, the radiation dose of the primary tumor was significantly higher than that in previous clinical studies. Overall, $78 \%$ of patients completed the prescription dose $(59.4 \mathrm{~Gy}$ in 33 fractions or $60 \mathrm{~Gy}$ in 30 fractions) of radiotherapy, the average radiation dose was $56.69 \mathrm{~Gy}$, and the average BED was $67 \mathrm{~Gy}$. Previous studies showed that a prescription dose of 54 Gy to $60 \mathrm{~Gy}$ (BED = 65 to $72 \mathrm{~Gy}$ ) delivered to rectal tumors would achieve a significant tumor regression effect, and the percentage of patients with tumor regression grade (TRG) 1 and 2 was approximately 60 to $63.9 \%[26,27]$.

In this study, Kaplan-Meier survival analysis showed that the median survival times of the primary tumor groups with and without radiotherapy were $20.07 \pm 8.98$ months and $17.33 \pm 7.34$ months, respectively. This was consistent with previous studies on stage IV colorectal cancer patients who only received chemotherapy (median survival was 16 to 20 months), so we decided to use the 18-month survival rate as the outcome variable in this study. Furthermore, in this study, the priori selection of covariates was based on previous studies and the experience of the authors but also considered the results of the univariate analysis. Subsequently, multivariate Cox regression analysis after adjusting for covariates, analysis after PSM, IPTW analysis and PS-adjusted model analysis were performed to examine the reliability of the results. All analyses consistently showed that primary tumor radiotherapy could effectively reduce the risk of death for these patients at 18 months. According to the results of the different analysis models above, although the hazard ratio (HR) increased significantly, the reduction in the risk of death did not change, and the range of the confidence interval gradually narrowed. Our results became more conservative and accurate with the IPTW and PS-adjusted model analyses. A retrospective observational study similar to this study showed that palliative radiotherapy could improve the survival of patients with metastatic rectal cancer [28]. However, several deficiencies exist in the study. The study did not further analyze the location of the lesion (primary or metastatic) targeted by palliative radiotherapy, and it did not consider the dose. Chemotherapy, as an important factor affecting the survival of patients with metastatic rectal cancer, was not analyzed in this study. These deficiencies have been corrected in this study.

There are still some shortcomings and limitations in this study: (1) the time range of eligible patients included in this retrospective study was from September 2008 to September 2017. During this period, the price of bevacizumab and cetuximab in China were high, and these drugs were not covered by local health care insurance. Patients could rarely afford these medications, so this study did not select patients who received bevacizumab or cetuximab. The lack of targeted drugs will definitely reduce the survival benefit of patients and may affect the benefits of radiotherapy for primary tumors. (2) Compared with the 12 cycles recommended by the guidelines, the median number of chemotherapy cycles in this study was relatively low, at only 7 cycles. Fewer chemotherapy cycles will reduce the therapeutic efficacy for all patients and may have an uncertain impact on the benefits of primary tumor radiotherapy. (3) This study was a realworld study (observational clinical study). There might be some confounding factors outside of clinical cognition and previous literature reports that may affect the accuracy of the research results.

\section{Conclusions}

In this study, compared with patients with stage IV rectal or rectosigmoid cancer who did not receive primary tumor radiotherapy, those who received primary tumor radiotherapy had a reduced risk of death for 18 months. The dose pattern of $59.4 \mathrm{~Gy}$ in 33 fractions or $60 \mathrm{~Gy}$ in 30 fractions was acceptable during concurrent chemotherapy. These doses of radiation for primary tumors might be considered not only to relieve symptoms but also to improve the survival of patients with inoperable metastatic rectal or rectosigmoid cancer. 


\section{Abbreviations}

AJCC: American joint commission on cancer; BED: Biologically equivalent dose; CT: Computed tomography; Gy: Gray; HR: Hazard ratio; IMRT: Intensitymodulated radiotherapy; IPTW: Inverse probability of treatment weighting; KPS: Karnofsky performance status; MRI: Magnetic resonance imaging; NCCN: National comprehensive cancer network; OS: Overall survival; PD: Progressive disease; PR: Partial response; PS: Propensity score; PSM: Propensity score matching; RCT: Randomized controlled trial; RECIST: Response evaluation criteria in solid tumors; SD: Stable disease; TRG: Tumor regression grade

\section{Acknowledgments}

I want to thank the staff member Ms. Huiqin Li at the Department of Epidemiological Investigation of Guizhou Cancer Hospital Cancer Therapy Center for her support and assistance with my research project, as well as for providing the dataset used in this study.

\section{Authors' contributions}

Gang Wang, Wen-ling Wang, and Hong-Min Dong made substantial contributions to the design of the clinical plan, selection protocol and the design of the methods used in this study. Gang Wang delineated all structures. All authors contributed significantly to the manuscript, read the manuscript, gave final approval for the version to be published, and take public responsibility for appropriate portions of the content.

\section{Funding}

This study was supported by the Joint Fund (QianKeHe LH [2015]7383) of Guizhou Science and Technology Department. The funders had no role in the study design, data collection and analysis, decision to publish, or preparation of the manuscript.

\section{Availability of data and materials}

The datasets generated and/or analyzed during the current study are not publicly available since the participants did not consent to share the data with third parties.

\section{Ethics approval and consent to participate}

The institutional ethics committee granted ethics approval for this study (SL201507004; Guizhou Cancer Hospital, Guiyang, People's Republic of China).

\section{Consent for publication}

All authors consent to publication.

\section{Competing interests}

The authors declare that they have no competing interests.

Received: 3 March 2020 Accepted: 17 May 2020

Published online: 27 May 2020

\section{References}

1. Siegel RL, Miller KD, Jemal A. Cancer statistics, 2019. CA A Cancer J Clin. 2019;69:7-34.

2. Xishan W. Epidemiological characteristics and prevention and control strategies of colorectal cancer in China and American. Chin J Colorectal Dis (Electronic Edition). 2019;8(01):7-11.

3. Cutsem EV, Nordlinger B, Adam R, et al. Towards a pan-European consensus on the treatment of patients with colorectal liver metastases. Eur J Cancer. 2006;42(14):0-2221.

4. Dawood O, Mahadevan A, Goodman KA. Stereotactic body radiation therapy for liver metastases. Eur J Cancer 2009; 45(17):0-2959.

5. Qin S, Li J, Wang L, et al. Efficacy and tolerability of first-line Cetuximab plus Leucovorin, fluorouracil, and Oxaliplatin (FOLFOX-4) versus FOLFOX4 in patients with RAS wild-type metastatic colorectal Cancer: the open-label, randomized, phase III TAILOR trial. J Clin Oncol. 2018;36(30): 3031-9.

6. Cremolini C, Loupakis F, Antoniotti C, et al. FOLFOXIRI plus bevacizumab versus FOLFIRI plus bevacizumab as first-line treatment of patients with metastatic colorectal cancer: updated overall survival and molecular subgroup analyses of the open-label, phase 3 TRIBE study. Lancet Oncol. 2015;16(13):1306-15.
7. Heinemann V, von Weikersthal LF, Decker T, et al. FOLFIRI plus cetuximab versus FOLFIRI plus bevacizumab as first-line treatment for patients with metastatic colorectal cancer (FIRE-3): a randomized, open-label, phase 3 trial. Lancet Oncol. 2014;15(10):1065-75.

8. Venook AP, Niedzwiecki D, Lenz HJ, et al. CALGB/SWOG 80405: Phase III trial of irinotecan/5-FU/leucovorin (FOLFIRI) or oxaliplatin/5-FU/ leucovorin (mFOLFOX6) with bevacizumab (BV) or cetuximab (CET) for patients (pts) with KRAS wild-type (wt) untreated metastatic adenocarcinoma of the colon or rec [J]. J Clin Oncol Official J Am Soc Clin Oncol. 2014;32(18_suppl):LBA3.

9. National Comprehensive Cancer Network, Clinical practice guidelines in oncology, Rectal Cancer version 1.2020, 2019.

10. Ko-Chao L, Yuche O, Wan-Hsiang H, et al. Meta-analysis of outcomes of patients with stage IV colorectal cancer managed with chemotherapy/ radiochemotherapy with and without primary tumor resection. Oncotargets Ther. 2016;9:7059-69.

11. Gulack BC, Nussbaum DP, Keenan JE, et al. Surgical resection of the primary tumor in stage IV colorectal cancer without metastasectomy is associated with improved overall survival compared with chemotherapy/radiation therapy alone. Dis Colon Rectum. 2016;59(4): 299-305.

12. Clancy $C$, Burke JP, Barry $M$, et al. A meta-analysis to determine the effect of primary tumor resection for stage IV colorectal cancer with unresectable metastases on patient survival. Ann Surg Oncol. 2014; 21(12):3900-8.

13. Cassidy J, Tabernero J, Twelves C, et al. XELOX (capecitabine plus oxaliplatin): active first-line therapy for patients with metastatic colorectal cancer. J Clin Oncol. 2004;22(11):2084-91.

14. Giacchetti S, Perpoint B, Zidani R, et al. Phase III multicenter randomized trial of oxaliplatin added to chronomodulated fluorouracil-leucovorin as first-line treatment of metastatic colorectal cancer. J Clin Oncol. 2000;18(1): 136-47.

15. Köhne $\mathrm{CH}$, van Cutsem E, Wils J, et al. Phase III study of weekly high-dose infusional fluorouracil plus folinic acid with or without irinotecan in patients with metastatic colorectal cancer: European Organisation for Research and Treatment of Cancer gastrointestinal group study 40986. J Clin Oncol. 2005; 23(22):4856-65.

16. Gelsomino F, Spallanzani A, Orsi G, Caputo F, Santini C, Cascinu S. To resect or not to resect: the hamletic dilemma of primary tumor resection in patients with asymptomatic stage IV colorectal cancer. Crit Rev Oncol Hematol. 2018;132:154-60.

17. Yun JA, Huh JW, Park YA, et al. The role of palliative resection for asymptomatic primary tumor in patients with unresectable stage IV colorectal cancer. Dis Colon Rectum. 2014;57(9):1049-58.

18. Cellini C, Hunt SR, Fleshman JW, Birnbaum EH, Bierhals AJ, Mutch MG. Stage IV rectal cancer with liver metastases: is there a benefit to resection of the primary tumor. World J Surg. 2010;34(5):1102-8.

19. Maroney S, de Paz CC, Reeves ME, et al. Benefit of surgical resection of the primary tumor in patients undergoing chemotherapy for stage IV colorectal Cancer with Unresected metastasis. J Gastrointest Surg. 2018; 22(3):460-6.

20. Lee KC, Ou YC, Hu WH, Liu CC, Chen HH. Meta-analysis of outcomes of patients with stage IV colorectal cancer managed with chemotherapy/ radiochemotherapy with and without primary tumor resection. Onco Targets Ther. 2016;9:7059-69.

21. Cameron MG, Kersten C, Vistad I, Fosså S, Guren MG. Palliative pelvic radiotherapy of symptomatic incurable rectal cancer - a systematic review. Acta Oncol. 2014;53(2):164-73.

22. 1 Picardi V, Deodato F, Guido A, et al. Palliative short-course radiation therapy in rectal Cancer: a phase 2 study. Int J Radiat Oncol Biol Phys. 2016; 95(4):1184-90.

23. Tyc-Szczepaniak D, Wyrwicz L, Kepka L, et al. Palliative radiotherapy and chemotherapy instead of surgery in symptomatic rectal cancer with synchronous unresectable metastases: a phase II study. Ann Oncol. 2013; 24(11):2829-34.

24. Bae $\mathrm{SH}$, Park W, Choi DH, et al. Palliative radiotherapy in patients with a symptomatic pelvic mass of metastatic colorectal cancer. Radiat Oncol. 2011;6:52.

25. Sager O, Dincoglan F, Demiral S, et al. A concise review of pelvic radiation therapy (RT) for rectal Cancer with synchronous liver metastases. Int J Surg Oncol. 2019:1-11. 
26. Alongi F, Fersino S, Mazzola $R$, et al. Radiation dose intensification in preoperative chemo-radiotherapy for locally advanced rectal cancer. Clin Transl Oncol. 2017;19(2):189-96.

27. Lupattelli M, Matrone F, Gambacorta MA, et al. Preoperative intensitymodulated radiotherapy with a simultaneous integrated boost

combined with Capecitabine in locally advanced rectal cancer: shortterm results of a multicentric study. Radiat Oncol. 2017;12(1):139.

28. Qi L. Zezhi, et al. palliative beam radiotherapy offered real-world survival benefit to metastatic rectal cancer: a large US population-based and propensity score-matched study. J Cancer. 2019;10(5):1216-25.

\section{Publisher's Note}

Springer Nature remains neutral with regard to jurisdictional claims in published maps and institutional affiliations.

Ready to submit your research? Choose BMC and benefit from:

- fast, convenient online submission

- thorough peer review by experienced researchers in your field

- rapid publication on acceptance

- support for research data, including large and complex data types

- gold Open Access which fosters wider collaboration and increased citations

- maximum visibility for your research: over $100 \mathrm{M}$ website views per year

At BMC, research is always in progress.

Learn more biomedcentral.com/submissions 